\title{
Birth outcomes of cases with right sided obstructive defects of heart-a population-based case-control study
}

\author{
Attila Vereczkey ${ }^{1}$, Zsolt Kósa ${ }^{1}$, Melinda Csáky-Szunyogh ${ }^{2}$, Róbert Urbán $^{3}$, Andrew E. Czeizel ${ }^{4^{*}}$ \\ ${ }^{1}$ Versys Clinics, Human Reproduction Institute, Budapest, Hungary \\ ${ }^{2}$ The Hungarian Congenital Abnormality Registry, National Institute for Health Development, Budapest, Hungary \\ ${ }^{3}$ Eötvös Loránd University, Department of Personality and Health Psychology, Budapest, Hungary \\ ${ }^{4}$ Foundation for the Community Control of Hereditary Diseases, Budapest, Hungary \\ *Corresponding author E-mail: czeizel@interware.hu
}

\begin{abstract}
Among structural birth defects, i.e. congenital abnormalities, the most common group includes congenital heart defects (CHDs), however, the underlying causes are unclear in the vast majority of cases. Different CHD cases as homogeneously as possible are planned to evaluate. Thus the medically recorded birth outcomes of lethal or surgically corrected cases with different groups of right sided obstructive defects of heart (RSODH) were evaluated. The population-based large dataset of the Hungarian Case-Control Surveillance of Congenital Abnormalities was used and date were analyzed between 1980-1996, including 200 live-born cases with isolated RSODH, 72, 137 and 108 had congenital stenosis of pulmonary valve, atresia/stenosis of tricuspid valve, Ebstein's anomaly, and atresia/stenosis of pulmonary artery, respectively compared to 304 matched controls and 38,151 population controls without any defects. A higher rate of preterm birth and low birthweight was found in cases with RSODH born in somewhat elder women with higher birth order and lower socioeconomic status. However, 4 groups of RSODH were different from epidemiological aspect, and the degree of intrauterine growth restriction depended on the group of RSODH and the sex of fetuses. The pathogenesis-oriented classification of RSODH is not associated with similar epidemiological birth outcomes of cases with different RSODH groups.
\end{abstract}

Keywords: atresia/stenosis of pulmonary artery, atresia/stenosis of tricuspid valve, congenital stenosis of pulmonary valve, Ebstein's anomaly, right sided obstructive defects of heart.

\section{Introduction}

Congenital heart defect (CHD) is the structural birth defect, i.e. congenital abnormality (CA) of heart and great vessels. CHDs are among the most prevalent and serious CAs with profound medical, psychosocial and economic consequences. The birth prevalence of CHDs depends on the age at examination, the sensitivity of the examination technique, the case definition and the types of cases included, therefore their reported rates are between 4 and 50 in different studies [1-6]. The care of infants/children with CHD has been revolutionized over the last decades with a much better chance for their survival [7]. Nevertheless, despite recent medical and surgical advances, CHDs still cause a large proportion of infant/child mortality and morbidity [8].

The major problem is that the underlying causes of CHDs have been obscured, and without the knowledge of risk factors for CHDs there is limited chance for their prevention. Recent progress in human genetics has resulted in the rapid identification of genes causing CHDs [9, 10]; however, the role of possible environmental factors in the origin of CHDs is unclear in the vast majority of patients [11, 12].

CHDs cannot be regarded as a single homogeneous CA because they have different manifestations, severity and etiology, thus the aim of our project is to evaluate the possible risks in the origin of CHD-entities as homogeneously as possible. We followed the categorization of CHDs used in The Baltimore-Washington Infant Study (BWIS) [13, 14] based mainly on the pathogenesis-oriented classification of CHD groups by Clark [15]. This classification combines congenital stenosis of pulmonary valve, congenital atresia/stenosis of tricuspid valve and congenital atresia/stenosis of pulmonary artery into the group of right sided obstructive defects of heart (RSODH).

From epidemiological aspect it is important to evaluate CHD-entities as homogeneously as possible, thus the birth outcomes of cases with different groups of RSODH were evaluated in the population-based Hungarian Case-Control Surveillance of Congenital Abnormalities (HCCSCA) [16]. 


\section{Methods}

\subsection{Cases and controls}

Patients with CA including RSODH as cases in the HCCSCA were selected from the Hungarian Congenital Abnormality Registry (HCAR) [17]. The reporting of cases with CA is mandatory for physicians to the HCAR. Autopsy was mandatory for all infant deaths and pathologists sent a copy of the autopsy report to the HCAR if defects were identified. Since 1984 prenatal diagnostic centers were also asked to report malformed fetuses diagnosed prenatally with or without elective termination of pregnancy to the HCAR.

Cases with isolated CAs (only one organ is affected, sometimes with more CAs as complex CAs) and multiple CAs (concurrence of two or more CAs in the same person affecting at least two different organ systems) were strictly differentiated in the HCAR. The recorded total (birth + fetal) prevalence of cases with CA was 35 per 1000 informative offspring (live-born infants, stillborn fetuses and electively terminated malformed fetuses) between 1980 and 1996 [17] and about $90 \%$ of major CAs were recorded in the HCAR [18].

Only those cases reported the first 3 months after the end of pregnancy were selected from the HCAR for the HCCSCA (77\% of all cases, the rest affected mainly with mild CA). In addition cases with CA-syndromes caused by gene mutations or chromosomal aberrations with preconception origin were excluded.

The so-called controls were defined as newborn infants without CA. The source of these controls was the National Birth Registry of the Central Statistical Office for the HCCSCA on the basis of case lists for each quarter of the years from the HCAR. In general two controls were matched to every case according to sex, birth week in the year when the case was born and district of parents' residence. If controls were twins, only one of these twin-pairs was randomly selected for the HCCSCA.

\subsection{Data of birth outcomes and mothers}

Mothers were asked in an explanatory letter to send us the prenatal maternity logbook and every medical record particularly the discharge summary of their delivery in the study pregnancy and their child's CA. These medical documents were sent back within 4 weeks. Maternal age and birth order (parity) were evaluated on the records of prenatal maternity logbook. In addition mothers were also requested to fill-in a structured questionnaire including their socio-demographic data and pregnancy history and send it back with signed informed consent. Gestational age was calculated from the first day of the last menstrual period. The definitions of birth outcomes are given in Table 1, and were evaluated on the basis of discharge summaries of deliveries in pregnant women.

The mean \pm S.D. time elapsed between the end of pregnancy and the return of the "information package" (including logbook, discharge summary, questionnaire and informed consent) in our prepaid envelope was $3.5 \pm 2.1$ and $5.2 \pm 2.9$ months in cases and controls, respectively.

In addition regional district nurses were asked to visit all non-respondent case mothers and to help them to fill-in the same questionnaire used in the HCCSCA and to evaluate the available medical documents. Unfortunately district nurses could visit only 200 non-respondent [19] and 600 respondent [20] control mothers in two validation studies because the ethics committee considered this follow-up to be disturbing for the parents of all healthy children. Our previous validation study showed the low reliability of maternal self-reported information regarding smoking and alcohol drinking during the study pregnancy [21], therefore these data were evaluated only in women visited at home based on the cross interview of mothers and other family members living together, and finally the so-called family consensus was recorded.

The necessary data were available for $96.3 \%$ of cases $(84.4 \%$ from replies and $11.9 \%$ from visits) and $83.0 \%$ of controls ( $81.3 \%$ from replies and $1.7 \%$ from visits). The flow of cases from the HCAR and controls from the Central Statistical Office to the HCCSCA was shown previously [22]. The signed informed consent was sent back by $98 \%$ of mothers, the name and address were deleted in $2 \%$ of subjects without signed informed consent.

The method of data collection was changed in 1997 after the retirement of last author in this paper, since all case and control mothers are visited and questioned at home by regional nurses, but these data have not been validated at the time of this analysis, and it explains why only the 17 years' data set of the HCCSCA, 1980-1996 is evaluated.

\subsection{Study design of RSODH}

We supposed that most surviving cases with CHD were cared or had surgical intervention in the pediatric cardiologic institutions in Hungary, therefore one of us (M. Cs-Sz.) visited these cardiologic in- and outpatients clinics in 2008. Medical records were reviewed and the previous diagnosis of specified CHD was checked (and corrected it if necessary) and the previous unspecified CHDs were modified to specified CHD-diagnoses. If cases with CHD were not 
found in the records of pediatric cardiologic institutions, we had a correspondence with their mothers to clarify the fate and/or diagnosis of these cases in 2009 and 2010. However, (i) if these cases were not found, (ii) CHD-diagnosis was not specified, or (iii) not confirmed, or (iv) mothers refused the collaboration, they were excluded from the study.

At the evaluation of RSODH we had 3 selection steps:

I. Cases with syndromic RSODH due to major mutant genes (e.g. Williams-Beuren or

Noonan) or chromosomal aberrations (e.g. Down) were excluded from the HCCSCA. Cases with unidentified multiple CA including RSODH were also excluded from the study.

II. Among cases with isolated RSODH, 4 groups were evaluated with the following criteria:

1. Congenital stenosis of pulmonary valve (CSPV). Our coding system was not able to differentiate complete obstruction (atresia) and partial obstruction (stenosis) of pulmonary valve. CSPV is characterized by the thickened and dome shaped pulmonary valve. Only cases with intact ventricular septum were included to the study, cases with absent of pulmonary valve, pulmonary valve regurgitation, infundibular and supravalvular pulmonary valve stenosis were excluded.

2. Congenital atresia/stenosis of tricuspid valve (ASTV) is a failure of communication from the right atrium to the right ventricle. ASTV is related with normal great vessels and may develop in mid and late pregnancy. Tricuspid atresia with ventricular septal defect or transposition of the great vessels is complex CHD and these cases are excluded from this study.

3. Ebstein's anomaly (EbA) is a CA of the tricuspid valve, first described by Wilhelm Ebstein [23] in 1866. EbA is characterized by a downward displacement of the attachment of the tricuspid valve into the inflow portion of the right ventricle.

4. Congenital atresia/stenosis of pulmonary artery (ASPA) with intact ventricular septum was evaluated in this study.

III. The 4 groups of RSODH have very wide spectrum of severity between the mild end of CSPV and the severe end of lethal EbA, therefore only severe cases, i.e. with lethal outcome (proved by autopsy reports) or after surgical management were included to the study, thus our cases represented the tip of iceberg.

First we evaluated cases with different groups of RSODH together due to the limited number of cases in different groups. However, different groups of RSODH were evaluated separately in the second step of the study.

Controls were differentiated into two groups: (i) matched controls without CA of cases with RSODH evaluated in the study and (ii) population controls, i.e. all controls without CA in the HCCSCA.

\subsection{Statistical analysis}

The software STATA 9.1 was used. First, we compared the sex, gestational age at delivery and birth weight of newborn infants, in addition maternal socio-demographic characteristics between cases with RSODH and controls using Student $\mathrm{t}$ test for quantitative while chi square test or odds ratio (OR) with $95 \%$ confidence interval (CI) for categorical variables. In the next step this analysis was repeated in the specified groups of RSODH and their matched controls. Among confounders we considered maternal age, birth order (parity) and pregnancy order, marital and employment status of mothers as indicator of socio-economic status [24].

\section{Results}

Our population-based data set included 200 live-born cases with RSODH, and the number of boys was 108 (54.0\%). The proportion of boys was $51.3 \%$ in the 2,138,151 Hungarian newborns during study period. Of 200 cases with RSODH, 72 (36.0\%) had CSPV, 13 (6.5\%) were affected with ASTV, 7 (3.5\%) had EbA and $108(54.0 \%)$ were recorded as ASPA. The number of matched and population controls was 304 and 38,151, respectively, the latter represented $1.8 \%$ of all live-births with good agreement in the birth outcomes of the Hungarian newborn population.

First live-birth outcomes of cases with RSODH together and of their matched and population controls are presented (Table 1). The mean gestational age at delivery was 0.6 and 0.4 week shorter in cases than in their matched and population controls. The rate of preterm births was 3.0 and 1.8 fold higher in the group of cases than in the groups of matched and population controls, respectively. The mean birth weight was nearly similarly smaller (266 and $273 \mathrm{~g})$ in cases than in matched and population controls in agreement with 4.0 fold higher rate of low birthweight. The lower mean birth weight could be explained only partly by the shorter gestational age thus there was intrauterine growth restriction in cases confirmed by the higher rate of low birthweight than preterm birth. 
Table 1: Live-birth outcomes of cases with RSODH, their matched and population controls

\begin{tabular}{|c|c|c|c|c|c|c|c|c|}
\hline Live-birth outcomes & \multicolumn{2}{|c|}{$\begin{array}{c}\text { Cases } \\
(\mathrm{N}=200)\end{array}$} & \multicolumn{3}{|c|}{$\begin{array}{l}\text { Matched controls } \\
\qquad(\mathrm{N}=304)\end{array}$} & \multicolumn{3}{|c|}{$\begin{array}{l}\text { Population controls } \\
\qquad(\mathrm{N}=38,151)\end{array}$} \\
\hline Categorical & No. & $\%$ & No. & $\%$ & OR $95 \%$ CI & No. & $\%$ & OR $95 \% \mathrm{CI}$ \\
\hline Twins & 1 & 0.5 & 7 & 2.3 & $0.210 .03-1.75$ & 410 & 1.1 & $0.46 \quad 0.06-3.31$ \\
\hline Preterm birth* & 33 & 16.5 & 17 & 5.5 & $3.341 .80-6.17$ & 3,496 & 9.2 & $1.96 \quad 1.35-2.85$ \\
\hline Postterm birth $* *$ & 2 & 1.0 & 5 & 1.6 & $0.600 .12-3.14$ & 151 & 0.4 & $2.540 .63-10.33$ \\
\hline Low birthweight**** & 46 & 23.0 & 18 & 5.8 & $4.752 .66-8.47$ & 2,167 & 5.7 & $4.963 .56-6.91$ \\
\hline Large birthweight $* * * *$ & 2 & 1.0 & 2 & 0.6 & 1.530 .2110 .92 & 315 & 0.8 & $1.21 \quad 0.30-4.91$ \\
\hline Quantitative & Mean & S.D. & Mean & S.D. & $\mathrm{t}=\quad \mathrm{p}=$ & Mean & S.D. & $\mathrm{t}=\mathrm{p}=$ \\
\hline Gestational age (wk) & 39.0 & 2.6 & 39.6 & & $\begin{array}{ll}3.0 & 0.003 \\
\end{array}$ & 39.4 & 2.1 & $\begin{array}{ll}2.7 & 0.007\end{array}$ \\
\hline Birth weight (g) & 3,003 & 704 & 3,269 & 505 & $4.9<0.001$ & 3,276 & 511 & $7.5<0.001$ \\
\hline
\end{tabular}

*less than 37 completed gestational weeks

$* * 42$ completed weeks or more

*** less than 2500 gram

$* * * *$ more than 4500 gram

Bold numbers show significant associations

Maternal variables of cases with RSODH and their controls are shown in Table 2. The mean maternal age was somewhat but not significantly higher in case mothers than in control mothers. The mean birth order was significantly higher in the mothers of cases than in the mothers of controls. The difference between mean birth order and mean pregnancy order (based on live- and stillbirth and miscarriages) was 0.3 in the mothers of cases, while this interval was 0.2 in the mothers of controls and it may indicate a somewhat higher rate of miscarriages in the previous pregnancies of case mothers. The rate of unmarried mothers did not show significant differences among the study groups. However, the proportion of semi- and unskilled workers, housewives (in Hungary most of these women belonged to the lower socioeconomic status) and others (mainly early pension due to disorders) was much higher in case mothers (43.5\%) than in matched $(27.4 \%)$ and population control (30.2\%) mothers.

Table 2: Main variables of mothers who delivered cases, matched and population controls

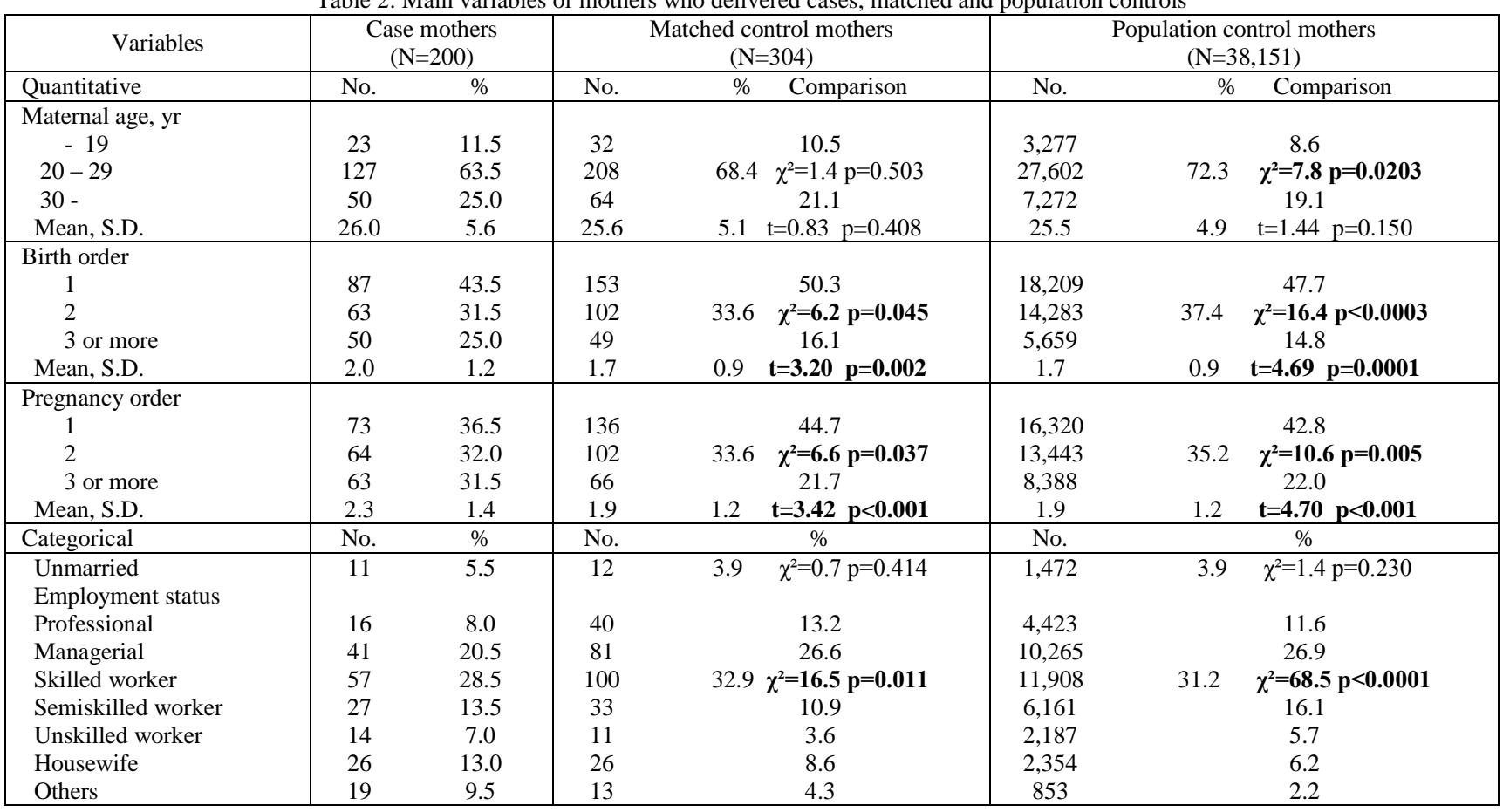

Bold numbers show significant associations

The main aim of the study was to evaluate the medically recorded birth outcomes of 4 RSODH groups separately (Table 3/A-B), though the limited number of cases with EbA and ASTV weakened the statistical power of this analysis.

The sex ratio of 72 cases with CSPV corresponded to the sex ratio of Hungarian newborn population while 13 cases with ASTV had a strong female excess. Some boy excess occurred among 108 cases with ASPA while obvious male predominance was characteristic for 7 cases with EbA.

The mean gestational age was shorter in all RSODH groups than in the Hungarian newborns (39.4 wk). However, the shortest was observed in cases with ASTV and EbA while the longest in cases with CSPV, and cases with ASPA had 
the intermediate position. The rate of preterm birth in all RSODH groups exceeded the 9.2\% figure of Hungarian newborns, but these rates were not in agreement with the mean gestational age because the highest rate was found in cases with ASPA. The mean birth weight was largest in cases with CSPV while the smallest in cases with EbA and ASTV but it was lower in all RSODH groups than in the Hungarian newborns $(3,276 \mathrm{~g})$. The evaluation of low birthweight rates showed the high figures in cases with ASTV (30.8\%), EbA (28.6\%), ASPA (25.0\%) and CSPV (18.1\%) compared to the rate of Hungarian newborns $(5.7 \%)$.

The youngest mean maternal age was observed in the group of cases with EbA. The mean birth order was higher in the mothers of cases with CSPV and ASPA, and the interval between birth and pregnancy order was somewhat longer (0.3) in these two groups of RSODH indicating a higher rate of miscarriages in the previous pregnancies of their mothers. There was no significant difference in the rate of unmarried mothers among different groups of RSODH. The proportion of low socio-economic status was very high in the groups of CSPV and ASPA but not in the groups of EbA and ASTV.

In the next step birth outcomes of cases with different groups of RSODH were compared with their matched controls (Table 3/A-B), however, the unusual low rate of preterm birth in matched controls is disturbing.

Cases with CSPV had 0.5 week shorter mean gestational age and 179 grams smaller mean birth weight than in their matched controls and these variables associated with 3.1 fold higher rate of preterm birth and with 5.0 fold higher rate of low birthweight. Thus mainly the higher rate of low birthweight is noteworthy.

The limited number of cases with ASTV had both shorter mean gestational age (1.5 wk) and smaller mean birth weight (336 g), in addition 2.9 fold higher rate of preterm birth and low birthweight compared to their matched controls.

Only 7 cases with EbA had 0.6 shorter mean gestational age, but 591 grams smaller mean birth weight than their 12 matched controls and the latter associated with very high rate of low birthweight.

The mean gestational age was 0.6 week shorter while their mean birth weight was 300 grams smaller in cases with ASPA than in their matched controls in agreement with 3.0 fold and 5.6 fold higher rate of preterm birth and low birthweight, respectively. Thus cases with ASPA had intrauterine growth restriction.

The comparison of maternal variables in cases and their matched controls showed a somewhat higher mean maternal age in the groups of RSODH cases but these differences were not significant. However, a higher birth/pregnancy order was found in the groups of CSPV and ASPA with 2.1 and 1.9 fold higher proportion of low socioeconomic status, respectively. Similar difference was not found in the groups of ASTV and EbA.

Finally the birth outcomes of cases with CSPV and ASPA were evaluated according to the sex of cases. In general female newborns have shorter gestational age and lower birth weight in agreement with somewhat higher rate of preterm birth and low birthweight.

Table 3/A: Live-birth outcomes and maternal socio-demographic variables of cases with CSPV and ASTV and their matched controls

\begin{tabular}{|c|c|c|c|c|c|c|c|c|c|c|}
\hline \multirow{2}{*}{$\begin{array}{l}\text { Study groups } \\
\text { Live births } \\
\text { Categorical }\end{array}$} & \multicolumn{2}{|c|}{$\begin{array}{c}\text { A/S of pulmonary } \\
\text { valve }(\mathrm{CSPV})^{*} \\
(\mathrm{~N}=72)\end{array}$} & \multicolumn{3}{|c|}{ Matched controls } & \multicolumn{2}{|c|}{$\begin{array}{l}\text { A/S of tricuspid } \\
\text { valve }(\mathrm{ASTV})^{*} \\
\quad(\mathrm{~N}=13)\end{array}$} & \multicolumn{3}{|c|}{ Matched controls } \\
\hline & No. & $\%$ & No. & $\%$ & OR $95 \% \mathrm{CI}^{* *}$ & No. & $\%$ & No. & $\%$ & OR $95 \% \mathrm{CI}^{* *}$ \\
\hline \multicolumn{11}{|l|}{ Newborns } \\
\hline Sex ratio (boy) & 37 & 51.4 & 60 & 49.6 & $1.070 .60-1.93$ & 5 & 38.5 & 5 & 26.2 & $\begin{array}{ll}1.75 & 0.39-7.95\end{array}$ \\
\hline Twins & 0 & 0.0 & 5 & 4.1 & N/A & 0 & 0.0 & 1 & 5.3 & $\mathrm{~N} / \mathrm{A}$ \\
\hline Preterm birth & 11 & 15.3 & 6 & 5.0 & 3.46 1.22-9.80 & 2 & 15.4 & 1 & 5.3 & $3.270 .26-40.47$ \\
\hline Low birthweight & 13 & 18.1 & 7 & 5.8 & $3.591 .36-9.48$ & 4 & 30.8 & 2 & 10.5 & $3.78 \quad 0.58-24.76$ \\
\hline \multicolumn{11}{|l|}{ Mothers } \\
\hline Unmarried & 5 & 6.9 & 4 & 3.3 & $2.180 .57-8.41$ & 0 & 0.0 & 0 & 0.0 & N/A \\
\hline Low SES*** & 33 & 45.8 & 26 & 21.5 & 3.09 1.64-5.83 & 3 & 23.1 & 6 & 31.6 & $0.650 .13-3.26$ \\
\hline Quantitative & Mean & S.D. & Mean & S.D. & $\mathrm{p}=$ & Mean & S.D. & Mean & S.D. & $\mathrm{p}=$ \\
\hline \multicolumn{11}{|l|}{ Newborns } \\
\hline Gestational age (wk) & 39.2 & 2.4 & 39.7 & 1.8 & 0.102 & 38.2 & 2.1 & 39.7 & 1.7 & $\begin{array}{ll}2.2 & 0.033 \\
\end{array}$ \\
\hline Birth weight (g) & 3,087 & 708 & 3,266 & 493 & 0.042 & 2,805 & 613 & 3,141 & 542 & $\begin{array}{ll}1.6 & 0.113 \\
\end{array}$ \\
\hline \multicolumn{11}{|l|}{ Mothers } \\
\hline Age (yr) & 26.0 & 5.3 & 25.4 & 4.9 & 0.426 & 25.0 & 4.1 & 24.6 & 4.7 & $0.2 \quad 0.805$ \\
\hline Birth order & 2.0 & 1.2 & 1.7 & 0.8 & 0.039 & 1.7 & 1.0 & 1.7 & 1.0 & $0.0 \quad 1.000$ \\
\hline Pregnancy order & 2.3 & 1.6 & 1.9 & 1.2 & 0.050 & 1.9 & 0.9 & 1.8 & 1.2 & 0.800 \\
\hline
\end{tabular}

$* \mathrm{~A} / \mathrm{S}=$ atresia/stenosis

** adjusted for maternal age, parity and SES

***Low SES=socioeconomic status: semi-or unskilled workers, housewives, and others

Bold numbers show significant associations 
Table 3/B: Live-birth outcomes and maternal socio-demographic variables in cases with EbA and ASPA and their matched controls

\begin{tabular}{|c|c|c|c|c|c|c|c|c|c|c|}
\hline \multirow{2}{*}{$\begin{array}{l}\text { Study groups } \\
\text { Live births } \\
\text { Categorical }\end{array}$} & \multicolumn{2}{|c|}{$\begin{array}{c}\text { Ebstein's anomaly } \\
(\mathrm{EbA}) \\
(\mathrm{N}=7)\end{array}$} & \multicolumn{3}{|c|}{ Matched controls } & \multicolumn{2}{|c|}{$\begin{array}{l}\text { A/S of pulmonary } \\
\text { artery (ASPA)* } \\
(\mathrm{N}=108)\end{array}$} & \multicolumn{3}{|c|}{ Matched controls } \\
\hline & No. & $\%$ & No. & $\%$ & OR $\quad 95 \% \mathrm{CI}^{* *}$ & No. & $\%$ & No. & $\%$ & $\begin{array}{l}\text { Comparison } \\
\text { OR } 95 \% \mathrm{CI}^{* * *}\end{array}$ \\
\hline \multicolumn{11}{|l|}{ Newborns } \\
\hline Sex ratio (boy) & 6 & 85.7 & 10 & 83.3 & $\begin{array}{c}1.20 \quad 0.09- \\
16.24\end{array}$ & 60 & 55.6 & 87 & 57.2 & $0.930 .57-1.54$ \\
\hline Twins & 0 & 0.0 & 0 & 0.0 & N/A & 1 & 0.1 & 1 & 0.7 & $1.410 .09-22.81$ \\
\hline Preterm birth & 1 & 14.3 & 0 & 0.0 & N/A & 19 & 17.6 & 9 & 5.9 & 3.39 1.47-7.83 \\
\hline Low birthweight & 2 & 28.6 & 0 & 0.0 & N/A & 27 & 25.0 & 7 & 4.6 & $6.902 .88-16.56$ \\
\hline \multicolumn{11}{|l|}{ Mothers } \\
\hline Unmarried & 1 & 14.3 & 0 & 0.0 & N/A & 5 & 4.6 & 8 & 5.3 & $0.870 .28-2.75$ \\
\hline Low SES*** & 1 & 14.3 & 2 & 16.7 & $0.830 .06-11.28$ & 49 & 45.4 & 36 & 23.7 & 2.68 1.57-4.56 \\
\hline Quantitative & Mean & S.D. & Mean & S.D. & $\mathrm{p}=$ & Mean & S.D. & Mean & S.D. & $\mathrm{p}=$ \\
\hline \multicolumn{11}{|l|}{ Newborns } \\
\hline Gestational age (wk) & 38.3 & 3.1 & 38.9 & 1.4 & $0.6 \quad 0.567$ & 38.9 & 2.8 & 39.5 & 1.9 & 2.10 .041 \\
\hline Birth weight (g) & 2,700 & 609 & 3,291 & 277 & $2.9 \quad 0.010$ & 2,996 & 726 & 3,296 & 513 & $3.9<0.0001$ \\
\hline \multicolumn{11}{|l|}{ Mothers } \\
\hline Age (yr) & 24.3 & 7.6 & 25.2 & 6.5 & $\begin{array}{ll}0.3 & 0.787 \\
\end{array}$ & 26.2 & 5.9 & 25.9 & 5.2 & $\begin{array}{ll}0.4 & 0.665 \\
\end{array}$ \\
\hline Birth order & 1.6 & 1.1 & 1.7 & 0.7 & 0.20 .810 & 2.1 & 1.4 & 1.8 & 1.0 & $\begin{array}{ll}2.0 & 0.045 \\
\end{array}$ \\
\hline Pregnancy order & 1.6 & 1.1 & 1.7 & 0.7 & 0.20 .810 & 2.4 & 1.4 & 2.0 & 1.2 & $\begin{array}{ll}2.5 & 0.014 \\
\end{array}$ \\
\hline
\end{tabular}

$* \mathrm{~A} / \mathrm{S}=$ atresia/stenosis

**adjusted for maternal age, parity and SES

*** Low SES=socioeconomic status: semi-or unskilled workers, housewives and others

$\mathrm{N} / \mathrm{A}=$ cases are not available

Bold numbers show significant associations

Table 4 shows the data of cases with CSPV and their matched controls. The difference in gestational age between males and females was similar ( 0.8 week) in cases and matched controls. However, mean birth weight in male cases was $509 \mathrm{~g}$ larger than in female cases and this difference was only $199 \mathrm{~g}$ between matched male and female controls. The rate of preterm birth did not show significant difference between female cases and their matched controls but there was 3.5 fold higher rate of low birthweight in female cases than in their matched controls. Thus the previously found adverse birth outcome pattern in cases with CSPV is explained by female cases including obvious intrauterine fetal growth restriction. In addition the mothers of female cases had a higher rate of miscarriages in the previous pregnancies due 0.5 differences between their mean pregnancy and birth order. There was no difference in proportion of unmarried and low socioeconomic status between the mothers of male and female cases.

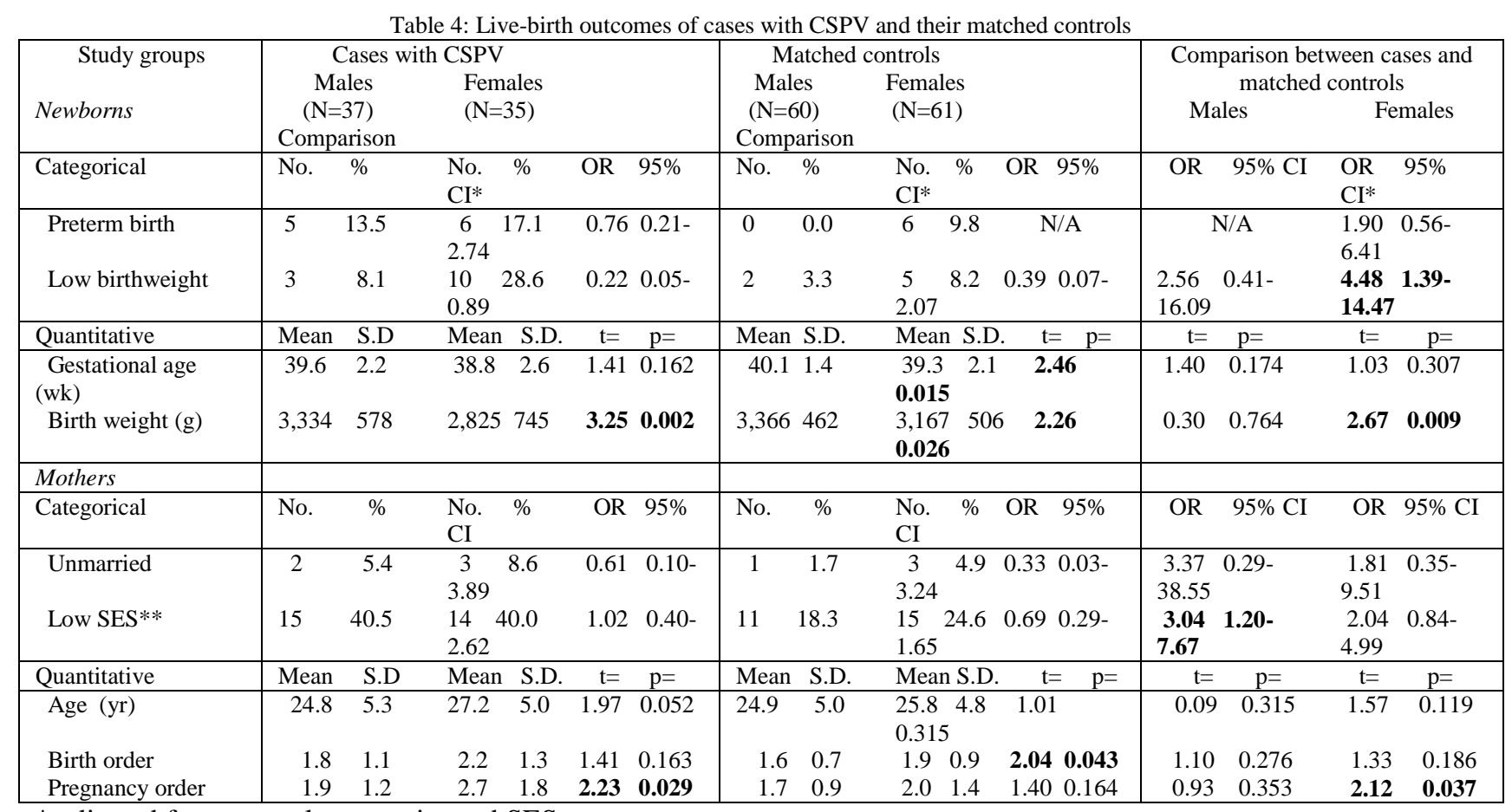

$*$ adjusted for maternal age, parity and SES 
**Low SES=socioeconomic status: semi-or unskilled workers, housewives, and others

$\mathrm{N} / \mathrm{A}=$ cases are not available

Bold numbers show significant associations

Mean gestational age and birth weight in male cases with ASPA was only 0.1 week longer and 97 grams larger than in female cases (Table 5). However, male cases had 0.8 week shorter gestational age and 378 grams smaller mean birth weight than their matched controls. These differences were only 0.4 week in mean gestational age and 193 grams in mean birth weight between female cases and their matched controls. The rate of preterm birth was 4.4 fold higher in male cases than in their matched male controls, while there was no difference in the rate of preterm birth between female cases and their matched controls. The rate of low birthweight was higher in both male (9.4 fold) and female (3.8 fold) cases than in their matched controls. Thus the birth outcome pattern was worse in male cases with ASPA. There was no difference in the maternal variables between male and female cases.

Table 5. Live-birth outcomes of cases with ASPA and their matched control

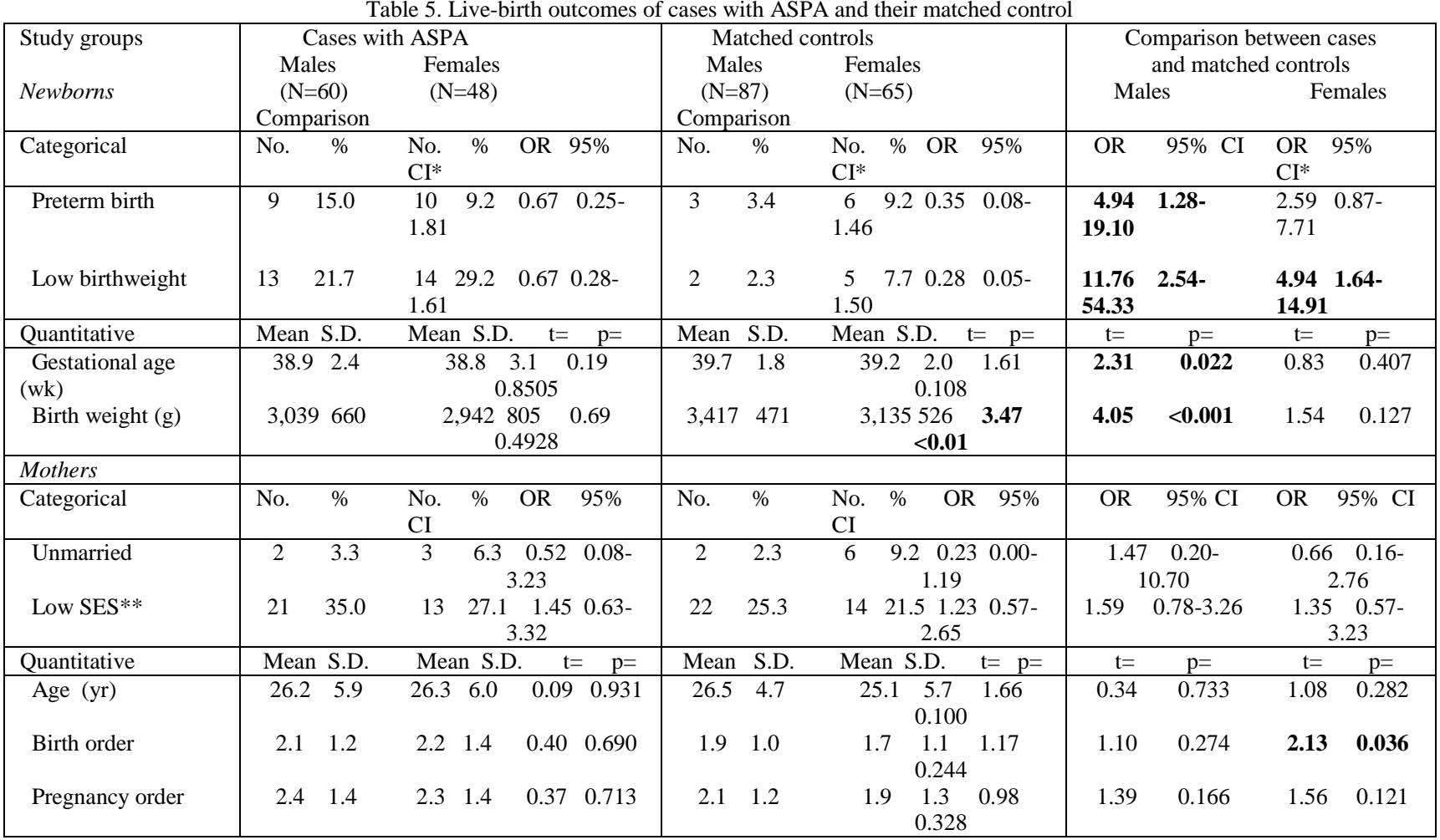

*adjusted for maternal age, parity and SES

**Low SES=socioeconomic status: semi-or unskilled workers, housewives, and others

Bold numbers show significant associations

\section{Discussion}

The findings of our study showed that the 4 groups of RSODH are not similar from epidemiological aspect because their sex ratio, birth outcomes, sex-modified intrauterine growth restriction and maternal variables were different. Thus intrauterine fetal growth restriction occurred only in female cases in the group of CSPV while a higher rate of preterm was observed in male cases in the group of ASPA. In addition the birth outcomes of matched controls showed larger similarity to cases with RSODH than population controls.

Previously a predominance of female infants with RSODH was observed [14, 25, 26]. Our cases with CSPV showed similar sex ratio as the Hungarian newborn population, cases with ASPA and EbA showed a mild and robust male excess, while cases with ASTV had female excess in this study.

The mothers of cases with CSPV and ASPA were somewhat elder with a significantly higher mean birth order. Data of maternal age and birth/pregnancy order were not published previously in cases with CSPV, EbA and ASPA [14, 27, 28]. Mothers of cases with ASTV were younger than mothers of controls in BWIS [14] similarly to our study. 
The lower socioeconomic status of mothers was characteristic for cases with CSPV and ASPA but not for cases with ASTV and particularly not for cases with EbA. There was a six-fold increase over controls of a low socioeconomic status in the mothers of cases with ASTV in BWIS [14, 29].

The main aim of this study was the description of birth outcomes in cases with different groups of RSODH. All cases with CSPV, ASPA, ASTV and EbA had shorter mean gestational age and smaller mean birth weight, associated with a higher rate of preterm birth and low birthweight. Similar findings were reported in cases with CSPV, ASTV and EbA in BWIS [14]. However, our study showed different pattern of births outcomes in these 4 RSODH groups with an obvious sex difference.

The question is whether these adverse birth outcomes are connected with RSODH [30] or some gene polymorphisms with fetal growth [31]. Confounding factors such as elder maternal age and lower socioeconomic status were considered at the calculated of adjusted figures.

Only 22 mothers of cases with RSODH were visited at home therefore our data are not appropriate for the evaluation of lifestyle.

The major finding of this study is that the pathogenesis-oriented classification of RSODH is not associated with similar epidemiological birth outcomes of cases with different RSODH groups.

The strengths of our study are connected with the large population-based data set of the HCCSCA in the ethnically homogeneous Hungarian (Caucasian) population in Hungary. We did our best to work with homogeneous subgroups of RSODH cases, therefore syndromic/multiple cases and mild cases without surgical correction were excluded from the study. The potential confounders were known.

However, there were some weaknesses of our study. The data of smoking and drinking habit were available only in 22 pregnant women and the number of cases with ASTV and EbA was limited for a detailed analysis.

In conclusion, our findings showed a higher rate of preterm birth and low birthweight in cases with RSODH born in somewhat elder women with higher birth order and lower socioeconomic status. However, 4 groups of RSODH were different from epidemiological aspect, and the degree of intrauterine growth restriction depended on the group of RSODH and the sex of fetuses

\section{Acknowledgement}

This project was supported by the Hungarian Egészségügyi Tudományos Tanács Pályázati Irodája (Grant Office of Scientific Committee of Health Ministry) and Versys Clinics, Human Reproduction Institute, Budapest, Hungary.

\section{References}

[1] Czeizel AE, Kamarás J, Balogh Ö, Szentpéteri J, "Incidence of congenital heart defects in Budapest”, Acta Paediat Acad Sci Hung, 13, 3, (1972), pp. 191-202.

[2] Hoffman JIE, Kaplan S, “The incidence of congenital heart disease”, J Am Coll Cardiol, 39, 12, (2002), pp. 1890-1900.

[3] Calzolary E, Garani G, Cocchi G, Magnani C, Rivieri F, Neville A, Astolfi G, Baroncini A, Garacelli L, Gualandi F, Scorrano M, Bosi G, IMFR Working Group, "Congenital heart defects: 15 years of experience of the Emilia-Romagna Registry (Italy)", Eur J Epid, 18, 8, (2003), pp. 773-780.

[4] Hoffman JIE, Kaplan S, Liberthson RR, "Prevalence of congenital heart disease”, Am Heart J, 147, 3, (2004), pp. 425-439.

[5] Dolk H. Loane M, Garne R, European Surveillance of Congenital anomalies (EUROCAT) Working Group, "Congenital heart defects in Europe: prevalence and perinatal mortality, 2000 to 2005", Circulation, 123, 8, (2011), pp. 841-849.

[6] Mészáros M, Nagy A, Czeizel AE, „Incidence of congenital heart disease in Hungary”, Hum Hered, 25, 6, (1975), pp. 513-519.

[7] Fulton DR, Congenital heart diseases in children and adolescent, In: Fuster V, Wals A, O’Rourke RA, Poole-Wilson P (eds.) Hurst's the Heart, 12th edn., New York, McGraw Hill Medical, (2008), pp. 1855-1921.

[8] Czeizel AE, Sankaranarayanan K, "The load of genetic and partially genetic disorders in man. Congenital anomalies: estimates of detriment in terms of years of life lost and years of impaired life", Mutat Res, 128, 1, (1984), pp. 73-103.

[9] Gelb BD, "Genetic basis of congenital heart disease", Curr Opin Cardiol, 19, 2, (2004), pp. 110-115.

[10] Pierpont ME, Basson CT, Benson DW, Gelb BD Jr, Giglia TM, Goldmuntz E, McGee G, Sable CA, Srivatava D, Webb CL, "Genetic basis for congenital heart defects: current knowledge", Circulation, 115, 23, (2007), pp. 3015-3038.

[11] Jenkins KJ, Correa A, Feinstein JA, Botto L, Britt AE, Daniels SR, Elixson M, Warnes CA, Webb CL, "Noninherited risk factors and congenital cardiovascular defects: current knowledge", Circulation, 115, 23, (2007), pp. 2995-3014.

[12] Rassmussen SA, Erickson JD, Reef SE, Ross DS, “Teratology: from science to birth defects prevention”, Birth Defects Res Part A Clin Mol Teratol, 85, 1, (2009), pp. 82-92.

[13] Ferencz C, Loffredo CA, Rubin JD, Magee CA, Epidemiology of Congenital Heart Diseases. The Baltimore-Washington Infant Study: 19811989, Future Publ. Co., Mount Kisco, N. Y., (1983).

[14] Ferencz C, Loffredo CA, Correa-Villasenor A, Wilson PD, Genetic and Environmental Risk Factors of Major Cardiovascular Malformations: The Baltimore-Washington Infant Study: 1981-1989, Futura Publ Co, Armonk, N. Y., (1997).

[15] Clark EB, Mechanism in the pathogenesis of congenital heart defects, In: Pierpont MEM, Moller JH (eds.): The Genetics of Cardiovascular Disease, Martinus-Nijoff, Boston, (1987), pp. 3-11. 
[16] Czeizel AE, Rockenbauer M, Siffel Cs, Varga E, "Description and mission evaluation of the Hungarian Case-Control Surveillance of Congenital Abnormalities, 1980-1996", Teratology, 63, 5, (2001), pp. 176-185.

[17] Czeizel AE, "The first 25 years of the Hungarian Congenital Abnormality Registry", Teratology, 55, 5, (1997), pp. 299-305.

[18] Czeizel AE, Intődy Zs, Modell B, “What proportion of congenital abnormalities can be prevented?”, Brit Med J, 306, 6876, (1993), pp. 499503.

[19] Czeizel AE, Petik D, Vargha P, "Validation studies of drug exposures in pregnant women”, Pharmacoepid Safety, 12, 5, (2003), pp. $409-416$.

[20] Czeizel AE, Vargha P, "Periconceptional folic acid/multivitamin supplementation and twin pregnancy", Am J Obstet Gynecol, 191, 3, (2004), pp. 790-794.

[21] Czeizel AE, Petik D, Puho E, "Smoking and alcohol drinking during pregnancy. The reliability of retrospective maternal self-reported information", Centr Eur J Publ Health, 12, 4, (2004) pp. 179-183.

[22] Ács N, Bánhidy F, Puho E, Czeizel AE, "Maternal influenza during pregnancy and risk of congenital abnormalities in offspring", Birth Defects Res Part A Clin Mol Teratol, 73, 12, (2005), pp. 989-995.

[23] Ebstein W, „Über einen sehr seltenen Fall von Insufficienz der Valvula Tricuspidalis, bedingt durch eine angeborene hochgradige Missbildung derselben“, Arch Anat Physiol Wissensch Med, 18, (1866), pp. 238-254.

[24] Puho E, Métneki J, Czeizel AE, "Maternal employment status and isolated orofacial clefts in Hungary", Centr Eur J Publ Health, 13, 3, (2005), pp. 144-148.

[25] Storch TG, Mannick EE, ,Epidemiology of congenital heart disease in Louisana: An association between race and sex and the prevalence of specific cardiac malformations", Teratology, 46, 3, (1992), pp. 271-276.

[26] Pradat O, Francannet C, Harris JA, Robert E, "The epidemiology of cardiovascular defects, part I. A study based on data from three large registries of congenital malformations", Pediatr Cardiol, 24, 3, (2003), pp. 195-221.

[27] Reefhuis J, Honein MA, "Maternal age and non-chromosomal birth defects, Atlanta 1968-200: teenager or thirty-something, who is at risk?", Birth Defects Res Part A Clin Mol Teratol, 70, 9, (2004), pp. 572-579.

[28] Miller A, Riehle-Colarusso T, Siffel C Frias JL, Correa A, "Maternal age and prevalence of isolated congenital heart defects in an urban area of the United States", Am J Med Genet A, 155A, 9, (2011), pp. 2137-2145.

[29] Correa-Villasenor A, McCarter R, Downing J, Ferencz C, "White-black differences in cardiovascular malformations in infancy and socioeconomic factors: the Baltimore-Washington Infant Study Groups", Am J Epidemiol, 134, 4, (1991), pp. 393-402.

[30] Rosenthal GL, "Patterns of prenatal growth among infants with cardiovascular malformations: Possible fetal hemodynamic effects", Am J Epidemiol, 143, 5, (1996), pp. 505-513.

[31] Freathy RM, Mook-Kanamori DO, Sovio U, Prokopenko I, Timpson NJ, Berry DJ, Washingtom NM, Widen F, Hottenga JJ, Kaakinen M, Lange LA, Gradfield JP, "Variants in ADCY5 and near CCNL1 are associated with fetal growth and birth weight", Nature Genet, 42, 5, (2010), pp. 430-435. 